\title{
Severe Plane-Form Enamel Hypoplasia in a Dentition from Roman Britain
}

\author{
Ian Towle ${ }^{1 *}$, Eleanor R. Dove ${ }^{1}$, Joel D. Irish ${ }^{1,2}$, Isabelle De Groote ${ }^{1}$ \\ ${ }^{1}$ Research Centre in Evolutionary Anthropology and Palaeoecology, School of Natural \\ Sciences and Psychology, John Moores University, Liverpool, United Kingdom \\ ${ }^{2}$ Evolutionary Studies Institute and Centre for Excellence in PaleoSciences, University \\ of the Witwatersrand, Private Bag 3, WITS 2050, South Africa
}

Keywords: Romano-British, dental enamel, dental defects

\begin{abstract}
Enamel defects can provide insight into the life histories of past individuals and populations, including information on a wide range of disturbances during childhood. This study investigates a particularly severe case of plane-form enamel hypoplasia from a Roman site in Gloucester, UK. Dentine protrudes above the occlusal enamel of upper central incisors, both upper canines, the lower left canine, lower right central incisor, and all four first molars. Given the morphology and location of these defects, along with the developmental timing of the affected teeth, such factors as molar-incisor hypomineralization, amelogenesis imperfecta, and congenital syphilis can likely be ruled out. The defects resulted from a nonspecific but severe physiological disturbance during the second year of life. Severe plane-form defects of this kind, where enamel formation has completely ceased, are extremely rare in premodern populations, and this example is one of the earliest reported cases. It has been suggested that these defects generally occur only in individuals that survived a life-threatening illness, which would explain the scarcity in the archaeological record, i.e., the afflicted individual would not have lived long enough for the defects to manifest. Comparisons with clinical examples and pathogen DNA analysis may provide further insight into the etiology of these defects.
\end{abstract}

Enamel hypoplasia is found in both modern and archaeological samples, in various forms and with different etiologies (e.g., Goodman et al., 1987; Lukacs et al., 2001; Guatelli-Steinberg et al., 2004; Ogden et al., 2007; Xing et al., 2015; Rohnbogner and Lewis, 2016). A range of causes can yield similar defects, making diagnosis in archaeological cases difficult. These defects nonetheless can often give insight into past populations, and further our understanding of health, diet, genetic disorders, and environmental stresses (MoggiCecchi et al., 1994; Hillson et al., 1998; Cunha et al., 2004; Crawford et al., 2007; Schuurs, 2012; GuatelliSteinberg et al., 2014). In this study, we investigate an exceptionally severe case of plane-form enamel hypoplasia in a dentition recovered from a Roman mass grave in Gloucester, UK. Comparisons are made with other archaeological examples as well as modern clinical case studies.

The affected individual was found in a mass grave containing 15 subadults and 76 adults, at a Roman site in Gloucester, UK (Simmonds et al., 2008). The remains were radiocarbon dated to the $1^{\text {st }}$ to $2^{\text {nd }}$ century AD. A multi-isotopic investigation was subsequently carried out by Chenery et al. (2010) on a sample of the skeletal remains, with results suggesting the grave consisted of a cross-section of the Gloucester population. Results are also indicative of diverse geographic origins for these individuals, whose diet was predominately terrestrial like that from other British Roman sites. The remains within the grave show no evidence of violence, and it has been suggested that they may be victims of an epidemic. Due to the time they could have been victims of the Antonine plague (Simmonds et al., 2008; Chenery et al., 2010).

Plane-form enamel hypoplasia, or PFEH, occurs when enamel matrix formation ceases entirely or in part, resulting in areas of an affected crown with little or no enamel deposition (Hillson and Bond, 1997; Ogden et al., 2007; Sawada et al., 2008; Krenz-Niedbała and Kozłowski, 2013). These defects have been described as extreme furrow-form defects, with one perikyma widened markedly. This exposed space comprises the large area of enamel matrix that was developing at the time and commonly displays Tomes process pits (Hillson, 2014). In rare circumstances the whole plane of the brown stria can be exposed down to the

\section{*Correspondence to:}

Ian Towle

Research Centre in Evolutionary Anthropology and Palaeocology, School of Natural Sciences and Psychology,

e-mail: I.Towle@2014.ljmu.ac.uk 
dentine surface; as noted by Hillson (2014), if such a defect occurs while the cusps are still forming, all of the above layers of matrix will be affected. Therefore, a relatively short, i.e., acute period of severe stress can potentially lead to a very large defect.

\section{MATERIALS AND METHODS}

The individual (Skeleton 1672) was recovered from a lower layer of the pit, and consists only of a fragmented skull, fragments of all cervical vertebrae and thoracic vertebral bodies, a rib fragment, and the left medial cuneiform; no pathological lesions are visible on these elements. The mandible and maxilla are fragmentary but otherwise well preserved - though all second and third molars are missing postmortem. Based on the morphology of the glabella and supraorbital ridge of the cranium, the individual was probably female (Walker, 2008). She would have been between 15-18 years of age at death (Simmonds et al., 2008). All material is housed at Liverpool John Moores University.

The dentition was first examined macroscopically, with a 10x hand lens used during the differential diagnosis to help confirm or discount conditions; further descriptions were based on images acquired using SEM. Each tooth was examined separately and any enamel defects were recorded and described. Other dental pathological conditions were also noted.

\section{RESULTS}

Enamel is completely or mostly absent near and on the occlusal surface of the upper central incisors, all first molars, upper canines, left lower canine, and right lower central incisor (Figs. 1 and 2). Dentine is exposed as an "island" above the surrounding enamel, and is clearly the result of an enamel defect at the time of for- mation rather than dental wear (Fig. 3). This is supported by the fact that the teeth most affected (first molars and upper central incisors) show negligible enamel wear and no evidence of weak or hypomineralisation/ hypocalcification enamel. Cervical to these defects the enamel immediately returns to normal and remains so on the rest of the crown surface.

The upper central incisors are most affected in terms of surface area, with PFEH across nearly the entire incisal edge. Only the mesial and distal extremities are not involved (Fig. 2A, B). The enamel located cervical to this defect appears normal and the overall tooth morphology does not evidence other abnormalities (Fig. 3). On the left central incisor, the defect is slightly more pronounced. The distance from the cementum enamel junction (CEJ) to the start of the defect (i.e. length of the normal enamel) is $7.95 \mathrm{~mm}$ and from the CEJ to the top of the exposed dentine, $9.40 \mathrm{~mm}$; therefore, the defect depth is a maximum of $1.45 \mathrm{~mm}$. Both measurements are from the center of the labial surface, where the exposed dentine is at its widest. The same measurements for the right incisor are $7.96 \mathrm{~mm}$, $9.27 \mathrm{~mm}$, and $1.31 \mathrm{~mm}$, respectively.

After the upper central incisors, the most affected teeth are the first molars. All have PFEH defects around the cusps (Fig. 2D, E, F). In the upper first molars the two distal cusps appear slightly more affected with more dentine exposed; in the lower counterparts the mesial buccal cusp appears slightly less affected. However, in both cases it should be emphasized that the exposed occlusal dentine is worn so a full assessment of the original morphology cannot be inferred.

Both upper canines have a distinct groove just below the cusp, with dentine exposed above. It is a PFEH defect, but because of wear the original extent is un-

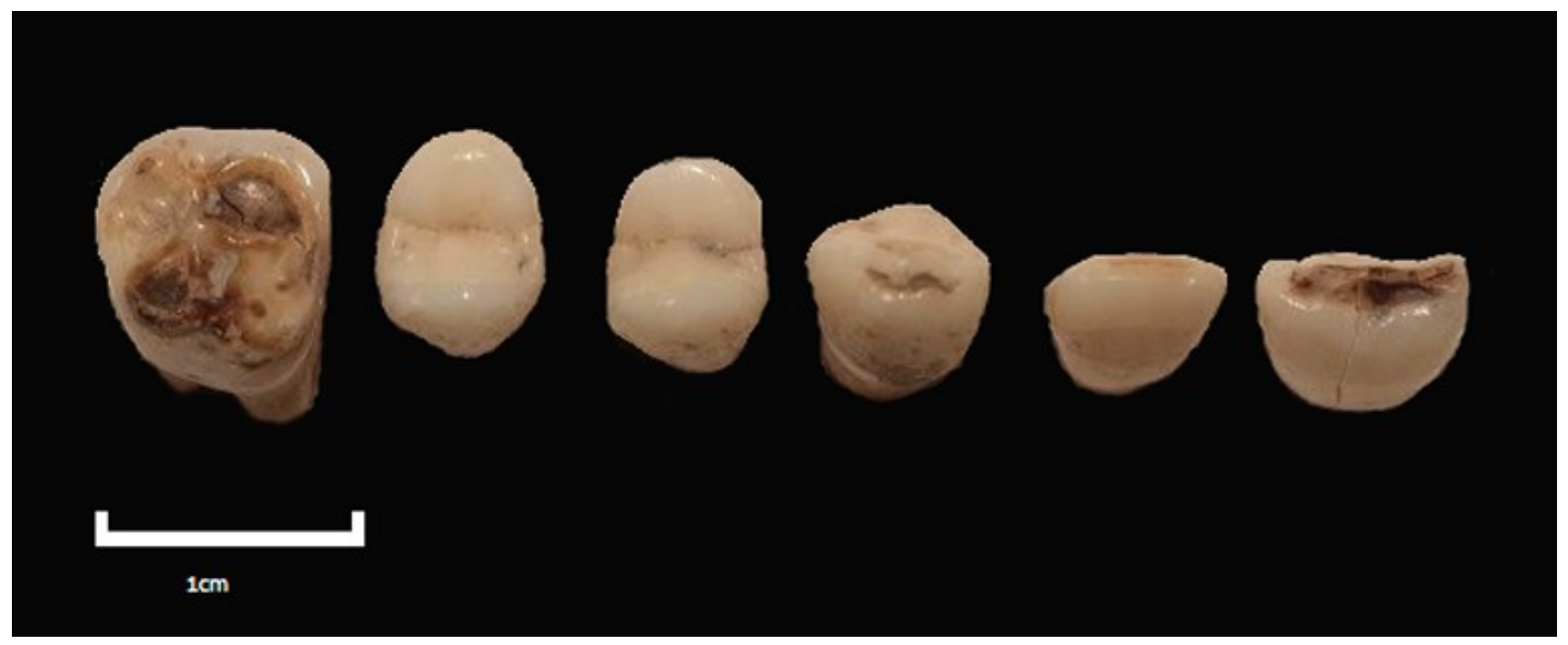

Figure 1. Occlusal view of the upper left permanent teeth of Skeleton 1672. From left to right: first molar, second premolar, first premolar, canine, lateral incisor and central incisor. 

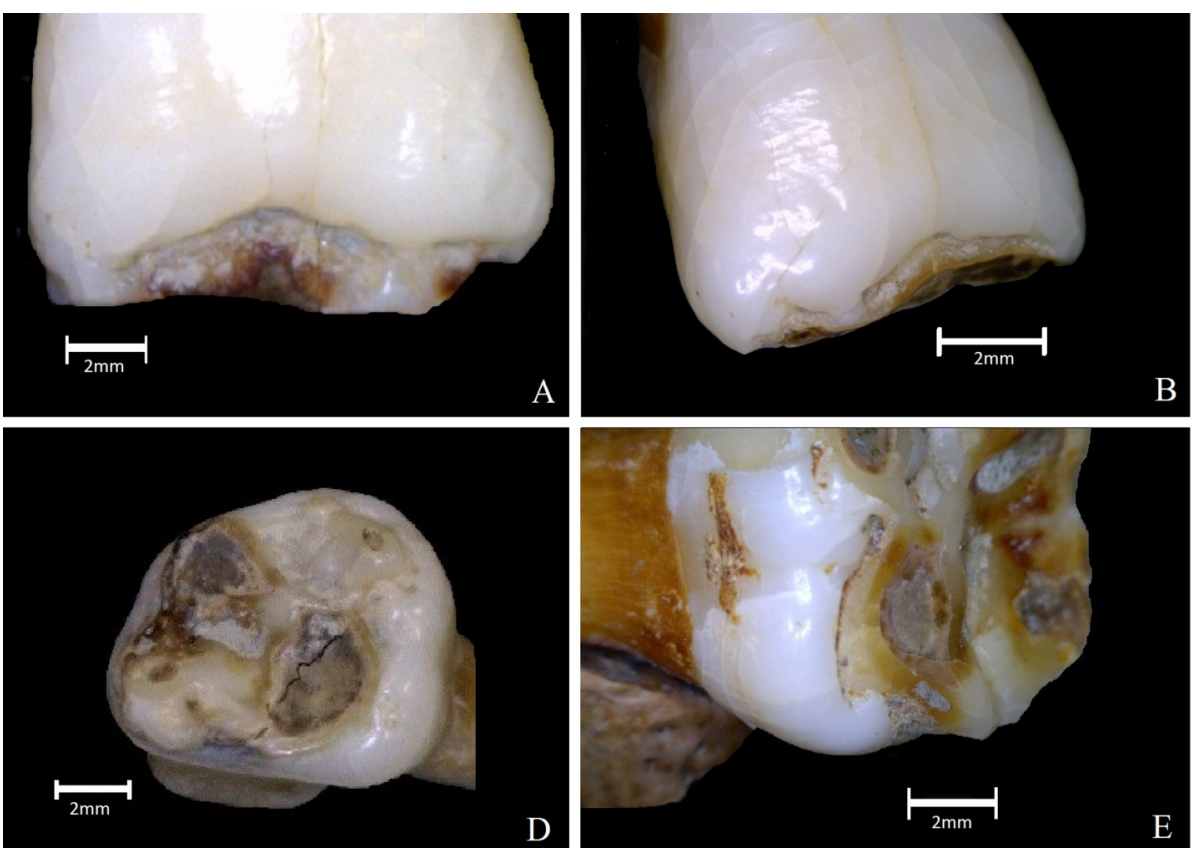
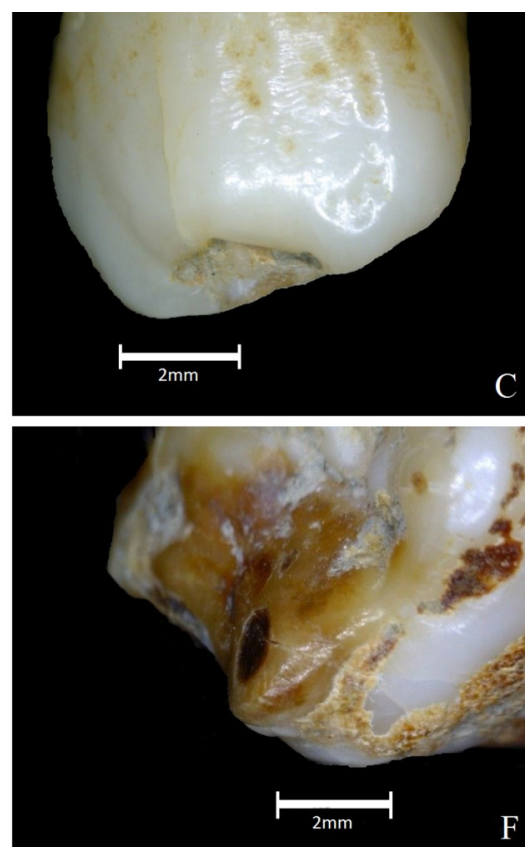

Figure 2. Teeth displaying plane-form enamel hypoplasia defects. (A) Upper left central incisor, labial view. (B) Upper right central incisor, labial view. (C) Upper right canine, labial view. (D) Upper left first molar, occlusal view. (E) Upper right first molar, lingual view. (F) Lower right first molar, mesial/lingual corner.

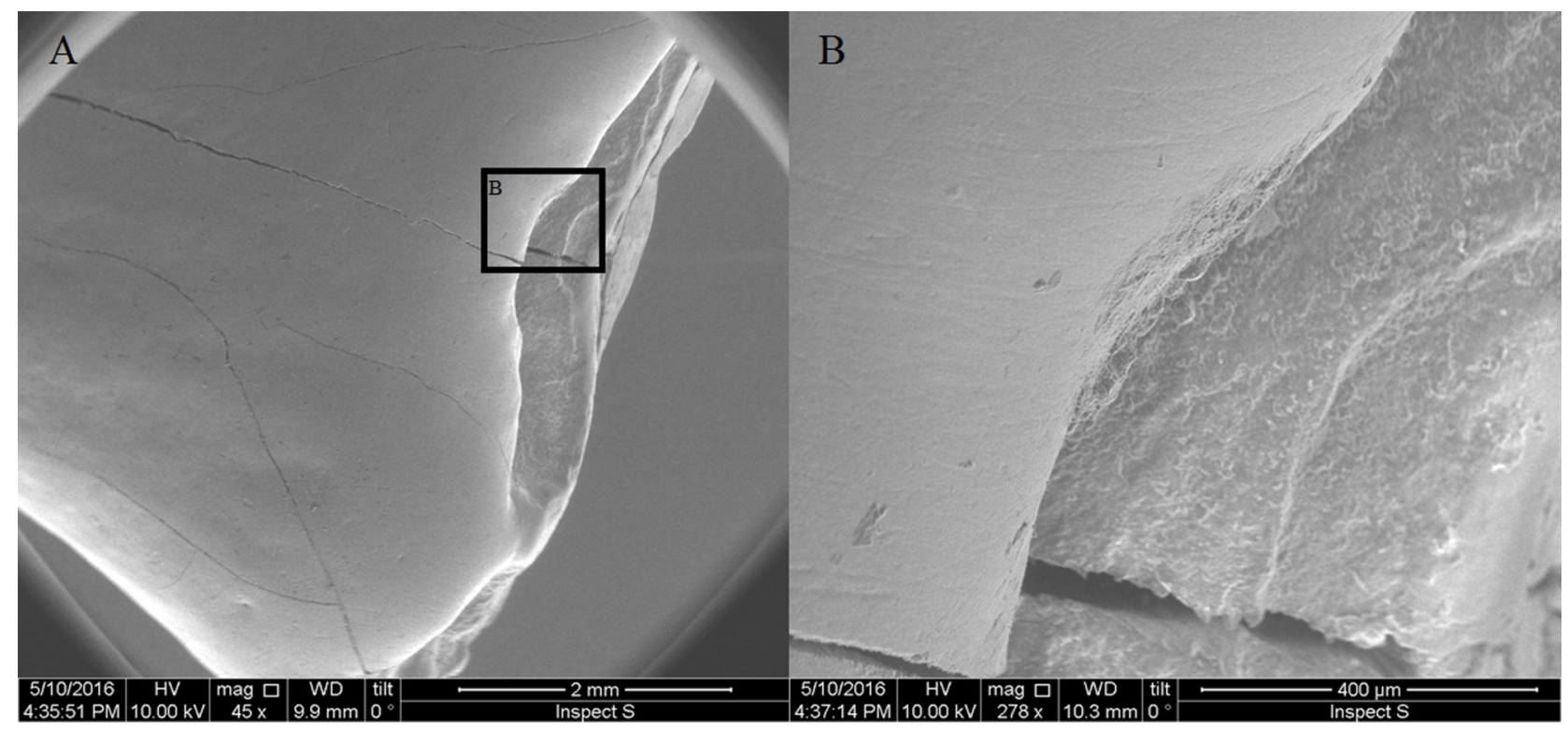

Figure 3. SEM of the upper right central incisor. (A) Showing the sharp contrast between the dentine on the occlusal surface and the enamel above. (B) A zoomed in view of the same surface to compare the textural differences between the surfaces. Note, post-mortem cracks on crown surface.

known. Under close inspection pitting enamel hypoplasia is evident on the mid-crown of the buccal sides, cervical to the PFEH (see Fig. 2C). The lower left canine is similarly affected but no defects were found on the lower right canine, likely due to wear.

The lower right central incisor has a PFEH defect toward the occlusal surface with dentine exposed, but to a lesser extent than the upper central incisors. The lower left central incisor does not display a defect; however, wear may have erased the evidence.

Extensive enamel pitting is present on the upper second premolars, particularly the lingual surface (Fig. 4A, B, C). These are mainly uniform small depressions that extend across the entire side, except near the CEJ. The buccal surface is also affected but the pitting is not as defined or uniform. Upper first premolars also exhibit pitting, but it is less defined than on the second premolars; again, they are more 
noticeable on the lingual surface. The lower premolars exhibit pitting, but is not overtly defined, i.e., it is barely discernible without use of the 10x lens.
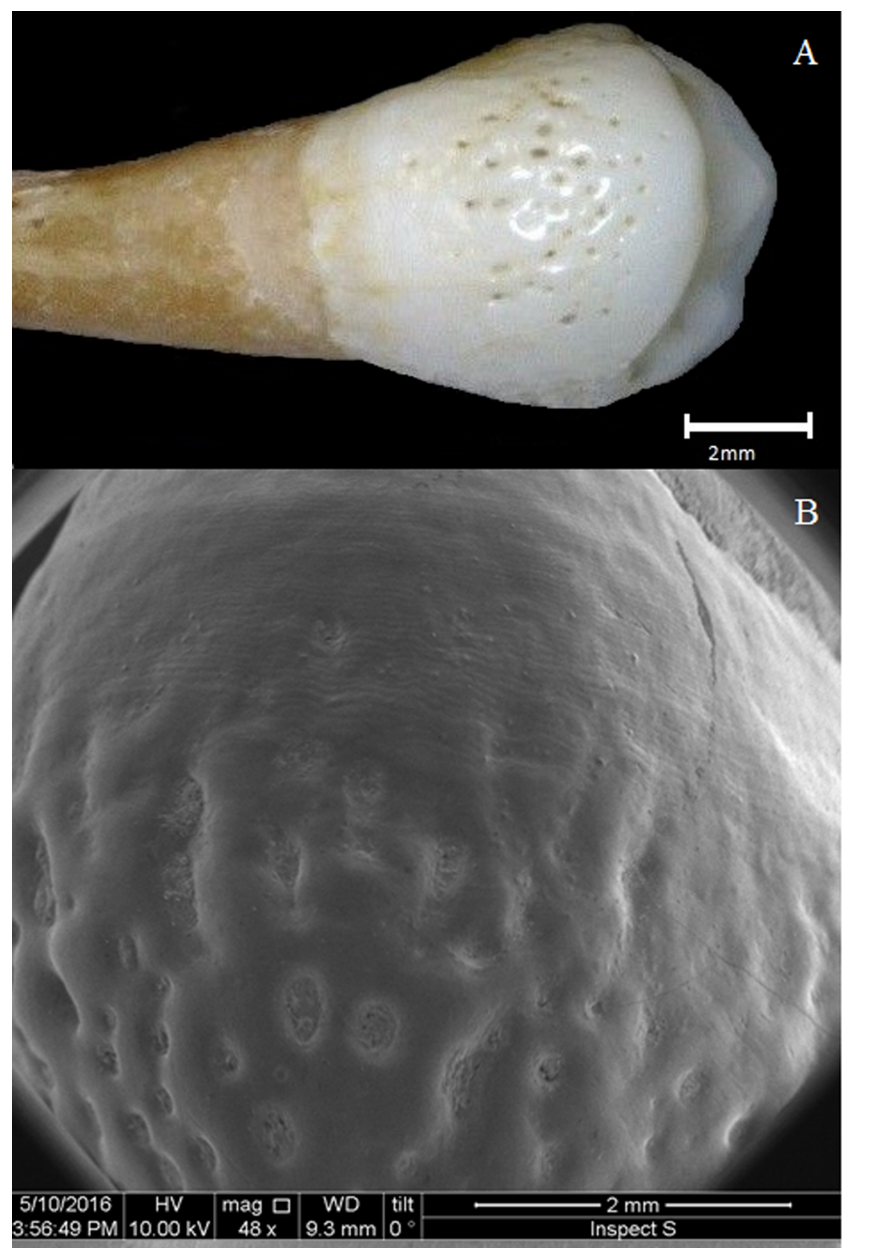

C

4:15:12 HV mag $\square$ WD tilt $=300 \mu \mathrm{m}$

Figure 4. Pitting enamel hypoplasia on the upper left second premolar, lingual surface. (A) Photograph of whole tooth. (B) SEM showing pitting and perikymata underneath. (C) Close-up SEM of one pit.
Although it is difficult to estimate the age at formation of PFEH defects (Hillson, 2014), it is possible to provide a rough estimate in this case due to multiple teeth sharing the defect across cusps. Using the chronological ages of enamel formation by Reid and Dean $(2000,2006)$ it was calculated that the defects on the central upper incisors, first molars, and canines fit with an episode of stress between 1 and 1.5 years of age (Fig. 5). The overlap in formation times and similarity in appearance indicate that these defects occurred concurrently, so were most likely caused by the same etiology. After about 1.6 years of age the enamelforming process returned to normal. It has been suggested that pitting enamel hypoplasia position on the crown may be only loosely related to timing of the disturbance (Hillson and Bond, 1997). However, the minimum age that this pitting could have formed on the upper premolars is at least one year after formation of the PFEH defects on the other teeth (Holt et al., 2012), so it certainly resulted from a later episode.

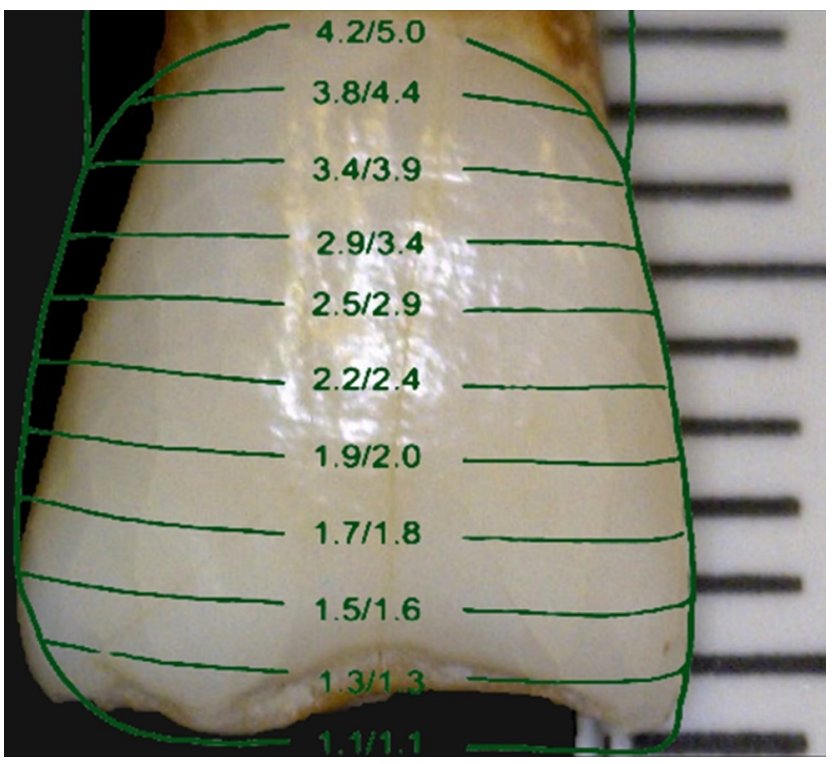

Figure 5. Upper right central incisor overlain with Reid and Dean (2000) chronological age of enamel formation, giving an estimate to the age the planeform defect occurred.

Pathological porosity within the observable mandibular alveoli may be suggestive of chronic infection. However, postmortem damage makes the full extent of this porosity difficult to understand. Radiographs do not show obvious large abnormalities nor evidence of abscess. Calculus is present on all teeth [1-2 in severity according to Brothwell (1981)]. The upper lateral incisors appear normal in morphology and enamel structure across the entire crown. Thus, the affected teeth suggest the disturbance responsible for the 
PFEH occurred in the second year of the individual's life, and was likely caused by a single exceptional episode.

\section{DIFFERENTIAL DIAGNOSIS}

Although PFEH is visible on multiple teeth, the relatively light occlusal wear means that the original scope of the hypoplasia may be erased to some degree, e.g., the lower right canine and lower central incisor. However, in the majority of teeth affected it is only the dentine that is worn, with the enamel relatively unworn even towards the occlusal surface. The pitting that is most defined and prevalent on the upper premolars is not found on teeth affected by PFEH, with the exception of the upper canines. The reason may relate to differences in formation and morphology between tooth classes and/or the location on the crown; however, it is also possible that two separate causes account for these alternate hypoplastic defects, or at least a change in severity.

Amelogenesis Imperfecta

There are several types of hereditary hypoplastic amelogenesis imperfecta and forms can vary among individuals (Wright, 1985; Aldred et al., 2003). It is rare, e.g., affecting one in every 700 to 14,000 people

(Sundell and Koch, 1984; Crawford et al., 2007). Enamel pitting, thinning, and PFEH are all associated with this condition (Mardh et al., 2002; Aldred et al., 2003;

Schuurs, 2012). However, thinning of enamel across the entire crown has also been reported, and all teeth may be affected regardless of formation time. This combination is not evident in the Roman dentition, i.e., sharp contrasts occur between defect and the enamel beneath. The age of defect formation also does not support this etiology. Superficially, the pitting looks like published examples of certain amelogenesis imperfecta types. However, this pitting is not found on the teeth with PFEH defects, except the canines, and these two defect types are usually associated with different types of amelogenesis imperfecta (Schuurs, 2012).

Molar incisor hypomineralisation

Another form of hypoplasia classified in recent years is molar incisor hypomineralisation (MIH) (Weerheijm, 2003; Ogden et al., 2007). This condition alters the translucency of enamel, which is of normal thickness but brown, white, or yellow in color (Weerheijm, 2003). It is included in this differential diagnosis because in some cases post-eruptive breakdown of enamel, which becomes soft and porous, can occur (Lygidakis et al., 2008). Although fitting this condition, in that the central incisors and first molars are most severely affected, it is unlikely that MIH is the cause. The defining enamel surface opacities are absent and the substantial areas of missing enamel appear to have been caused at the time of formation (see Fig. 3).

Congenital syphilis

It is difficult to diagnose congenital syphilis in archaeological material for many reasons, including contradictions in the original descriptions, lack of reference material, and high variability in form (Hillson et al., 1998; Ioannou et al., 2015). Defects in this individual are in the correct location and fit the description of PFEH in the mulberry molar form of congenital syphilis, i.e., a clear PFEH defect cuts sharply across the base of the cusps (Fournier, 1884; Putkonen, 1963; Hillson et al., 1998). Congenital syphilis also commonly affects the same teeth noted in this study. A PFEH defect is present around the tip of two canines, which is also a characteristic (Fournier, 1884; Hillson et al., 1998).

Nevertheless, there are several reasons to reject a congenital syphilis diagnosis. First, the most characteristic feature is absent - Hutchinson's incisors. The incisal edges of the upper incisors are not shortened, and no characteristic notches or bulging on the distal or mesial surfaces occur. The first molars do not evidence features associated with Moon's molars, i.e., abnormal cusp spacing or crown side bulging. As mentioned, mulberry molars do show PFEH defects, but are usually associated with a change in cuspal morphology not found here. However, not all cases of congenital syphilis possess these diagnostic features (Putkonen, 1963). Hillson et al. (1998) notes that PFEH defects in individuals with mulberry molars can also be caused by a range of other factors, so cannot be used in isolation to diagnose an archaeological case. A lack of definitive evidence for the presence of syphilis in England at this time also makes such a possibility unlikely.

It is worth noting that ingestion of high levels of a toxic compound such as mercury during the developmental period can result in PFEH (Ioannou et al., 2015). Mercury was used extensively in recent times to treat illnesses, particularly those affecting the skin like congenital syphilis and leprosy; however, at present there is little evidence that mercury was used to treat illnesses in Roman Britain.

Plane-form enamel hypoplasia with nonspecific cause Hillson and Bond (1997) demonstrate that PFEH defects occur when a plane of a brown stria of Retzius is left wholly or partially exposed, leading to a sharp step on the cervical edge of the defect where normal enamel formation resumes. Such cases can affect multiple striae of Retzius, leading to a step appearance near the occlusal surface. The latter is not evident in the present specimen; rather, a marked step directly below the defect is present in all affected teeth, followed by normal enamel along the rest of the crown height. Therefore, the episode that initiated the defect was likely of short duration. 


\section{DISCUSSION AND CONCLUSIONS}

By far the most common enamel hypoplasia defect is linear in form, with rates in populations varying substantially (Guatelli-Steinberg, 2015). In this Roman Gloucester site $28.5 \%$ of all teeth exhibit linear enamel hypoplasia (LEH) (Simmonds et al., 2008). Pitting is less common, though it is regularly reported in archaeological remains within LEH bands or scattered across the crown in a range of shapes and sizes (Ogden et al., 2007; Guatelli-Steinberg, 2015). It is unclear why in some cases pitting and others LEH occurs (Lovell and Whyte, 1999). PFEH is, in contrast, rare, which may in part be due to researchers simply including it as LEH (e.g., Goodman et al., 1987); however, the primary reason is likely related to high mortality rates in individuals who experienced circumstances that caused the defects. Occlusal wear also likely reduces the true number of cases observable in the archaeological record.

Although severe PFEH has not been described in remains from Roman Britain before, there is extensive literature on developmental defects, and more generally bioarchaeological research, for this time period (e.g., Simmonds et al., 2008; Pitts and Griffin, 2012; Redfern et al., 2015; Rohnbogner \& Lewis, 2016). The overall diet of individuals in Roman Britain would likely have been much broader than earlier periods, and there was variation in the foods eaten based on the site, sex, social status, and cultural background of each individual (King, 1999; Cool, 2006; van der Veen, 2008; Rohnbogner \& Lewis, 2016). Additionally, a variety of diseases and illnesses have been described in populations from this time period (Roberts and Cox, 2003; Lewis, 2010; Redfern et al., 2015). Therefore, the relatively high rates of enamel hypoplasia in Roman British populations may relate to a variety of factors, yet the example presented in this case study stands out due to its severity. This may reflect a more severe episode than those in other individuals with LEH defects, or may be due to a different etiology. However, either way what is noteworthy is this individual went on to survive for well over a decade after these defects formed. Perhaps therefore the lack of such defects in the archaeological record also reflects the fact extensive care is needed for an individual to overcome such a disturbance event.

Although PFEH defects have been reported in earlier fossil and archaeological hominins, they have either not been severe or the process of formation has been different, with localized hypoplasia often referred to as a PFEH defect (see Skinner et al., 2016). We differentiate between PFEH and localized hypoplasia because it is clear that in this case the defects are systemic. There are clear PFEH in some individuals dated to medieval times, in which congenital syphilis was suggested to be the cause (e.g., Lauc et al., 2015; Ioannou et al., 2015). Witzel et al. (2008) also present cases of PFEH in a medieval sample, but they are of a lesser severity with the dentine not exposed. Other more recent examples also exist, either caused by congenital syphilis or other physiological disturbance (e.g., Karnosh, 1926; Boyde, 1970; Hillson and Bond, 1997; Lambert, 2006; Ogden et al., 2007). However, it is clinical studies that offer the best comparative examples [e.g., Figure 3 of Wong (2014)].

A potential example that predates the case study presented here is from a Neolithic individual from present day Japan (Sawada et al., 2007). This individual shows extensive plane-form defects that superficially resemble those in this study. The main differences between the defects described in their study and the one presented here are that the Neolithic example has enamel hypocalcification involvement and no exposed dentine.

Karnosh (1926) highlights defects on anterior teeth of individuals without congenital syphilis; one is a PFEH defect with all properties seen in the present individual. These defects were thought by the author to have been caused by nutritional upset and acute infections. Similar defects were thought by Boyde (1970) to result from major disturbances in metabolism. It has been suggested that such a severe defect, where enamel formation ceases completely, would result from two or more combined stresses (Hillson, 2005). In any case, it is clear that severe illness or other episode of non-specific physiological stress is needed (Ogden et al., 2007; GuatelliSteinberg, 2015). The fact the enamel cervical to the PFEH returns to normal so sharply suggests that the individual may have quickly recovered from this episode. However, the enamel pit defects on later developing teeth suggest continued poor health in childhood after the initial, severe illness. The potential for a chronic infection in the maxilla and mandible may also hint at this individual's continued poor health after eruption of her permanent teeth; however, it cannot be determined if these three separate defects and other pathologies have the same etiology.

In sum, we have described one of the earliest known examples of severe PFEH, in which enamel did not form over large parts of the crown in multiple teeth. Although a specific etiology could not be established, we did rule out three potential causes: amelogenesis imperfecta, molar incisor hypomineralisation, and congenital syphilis. Clearly, this individual was exposed to a serious disturbance during development, and when more examples of this type of defect are described in the literature a better understanding 
of plane-form hypoplasia can be explored. Mercury testing, pathogen DNA analysis, and comparisons with a larger database of modern clinical examples should provide further evidence regarding the etiology of these defects.

\section{ACKNOWLEDGMENTS}

We would like to thank Paul Gibbons for access and help with the SEM and The Museum of Gloucester for access and support in studying the skeletal collection housed at Liverpool John Moores University.

\section{LITERATURE CITED}

Aldred, M., Savarirayan, R., \& Crawford, P. (2003). Amelogenesis imperfecta: A classification and catalogue for the 21st century. Oral Diseases, 9, 1923.

Boyde, A. (1970). The surface of the enamel in human hypoplastic teeth. Archives of Oral Biology, 15, 897898.

Brothwell, D. R. (1981). Digging up bones: The excavation, treatment, and study of human skeletal remains. Ithaca: Cornell University Press.

Chenery, C., Mueldner, G., Evans, J., Eckardt, H., \& Lewis, M. (2010). Strontium and stable isotope evidence for diet and mobility in Roman Gloucester, UK.. Journal of Archaeological Science, 37, 150163.

Cool, H. E. (2006). Eating and drinking in Roman Britain. Cambridge: Cambridge University Press.

Crawford, P. J., Aldred, M., \& Bloch-Zupan, A. (2007). Amelogenesis imperfecta. Orphanet Journal of Rare Diseases, 2, 17.

Cunha, E., Rozzi, F. R., Bermúdez de Castro, J., Martinón-Torres, M., Wasterlain, S., \& Sarmiento, S. (2004). Enamel hypoplasias and physiological stress in the Sima de los Huesos Middle Pleistocene hominins. American Journal of Physical Anthropology, 125, 220-231.

Fournier, A., \& White, J. W. (1884). Syphilitic teeth. SS White Dental Manufacturing Company.

Goodman, A. H., Allen, L. H., Hernandez, G. P., Amador, A., Arriola, L. V., Chavez, A., \& Pelto, G. H. (1987). Prevalence and age at development of enamel hypoplasias in Mexican children. American Journal of Physical Anthropology, 72, 7-19.

Guatelli-Steinberg, D., Larsen, C. S., \& Hutchinson, D. L. (2004). Prevalence and the duration of linear enamel hypoplasia: a comparative study of Neandertals and Inuit foragers. Journal of Human Evolution, 47, 65-84.

Guatelli-Steinberg, D., Stinespring-Harris, A., Reid, D. J., Larsen, C. S., Hutchinson, D. L., \& Smith, T. M. (2014). Chronology of linear enamel hypoplasia formation in the Krapina Neanderthals.
PaleoAnthropology, 431-445.

Guatelli-Steinberg, D. (2003). Macroscopic and microscopic analyses of linear enamel hypoplasia in Plio-Pleistocene South African hominins with respect to aspects of enamel development and morphology. American Journal of Physical Anthropology, 120, 309-322.

Guatelli-Steinberg, D. (2015). Micro-to macroscopic. In: Irish, J. D., \& Scott, G. R. (Eds.), A companion to dental anthropology, 450. Hoboken: WileyBlackwell.

Hillson, S. (2005). Teeth. Cambridge: Cambridge University Press.

Hillson, S. (2014). Tooth development in human evolution and bioarchaeology. Cambridge: Cambridge University Press.

Hillson, S., \& Bond, S. (1997). Relationship of enamel hypoplasia to the pattern of tooth crown growth: A discussion. American Journal of Physical Anthropology, 104, 89-103.

Hillson, S., Grigson, C., \& Bond, S. (1998). Dental defects of congenital syphilis. American Journal of Physical Anthropology, 107, 25-40.

Holt, S. A., Reid, D.J., \& Guatelli-Steinberg, D. (2012). Brief communication: Premolar enamel formation: Completion of figures for aging LEH defects in permanent dentition. Dental Anthropology, 343,4 .

Ioannou, S., Henneberg, M., Henneberg, \& R. J., Anson, T. (2015). Diagnosis of mercurial teeth in a possible case of congenital syphilis and tuberculosis in a 19th century child skeleton. Journal of Anthropology, 2015.

Karnosh, L. J. (1926). Histopathology of syphilitic hypoplasia of the teeth. Archives of Dermatology and Syphilology, 13, 25-42.

King, A. (1999). Diet in the Roman world: a regional inter-site comparison of the mammal bones. Journal of Roman Archaeology, 12, 168-202.

Krenz-Niedbała, M., \& Kozłowski, T. (2013). Comparing the chronological distribution of enamel hypoplasia in Rogowo, Poland (2nd century AD) using two methods of defect timing estimation. International Journal of Osteoarchaeology, 23, 410420.

Lambert, P. M. (2006). Infectious disease among enslaved African Americans at Eaton's Estate, Warren County, North Carolina, ca. 1830-1850. Memórias do Instituto Oswaldo Cruz, 101, 107-117.

Lauc, T., Fornai, C., Premužić, Z., Vodanović, M., Weber, G. W., Mašić, B., \& Šikanjić, P. R. (2015). Dental stigmata and enamel thickness in a probable case of congenital syphilis from XVI century Croatia. Archives of Oral Biology, 60, 1554-1564.

Lewis, M. E. (2010). Life and death in a civitas capital: 
metabolic disease and trauma in the children from late Roman Dorchester, Dorset. American Journal of Physical Anthropology, 142, 405-416.

Littleton, J., \& Townsend, G. (2005). Linear enamel hypoplasia and historical change in a central Australian community. Australian Dental Journal, 50, 101-107.

Lovell, N. C., \& Whyte, I. (1999). Patterns of dental enamel defects at ancient Mendes, Egypt. American Journal of Physical Anthropology, 110, 69-80.

Lukacs, J. R., Nelson, G. C., \& Walimbe, S. R. (2001). Enamel hypoplasia and childhood stress in prehistory: new data from India and Southwest Asia. Journal of Archaeological Science, 28, 1159-1169.

Lygidakis, N. A., Dimou, G., \& Marinou, D. (2008). Molar-incisor-hypomineralisation (MIH). A retrospective clinical study in Greek children. II. Possible medical aetiological factors. European Archives of Paediatric Dentistry, 9, 207-217.

Mardh, C. K., Bäckman, B., Holmgren, G., Hu, J. C. C., Simmer, J. P., \& Forsman-Semb, K. (2002). A nonsense mutation in the enamelin gene causes local hypoplastic autosomal dominant amelogenesis imperfecta (AIH2). Human Molecular Genetics, 11, 1069-1074.

Moggi-Cecchi, J., Pacciani, E., \& Pinto-Cisternas, J. (1994). Enamel hypoplasia and age at weaning in 19th-century Florence, Italy. American Journal of Physical Anthropology, 93, 299-306.

Ogden, A. R., Pinhasi, R., \& White, W. (2007). Gross enamel hypoplasia in molars from subadults in a 16th-18th century London graveyard. American Journal of Physical Anthropology, 133, 957-966.

Pitts, M., \& Griffin, R. (2012). Exploring health and social well-being in late Roman Britain: an intercemetery approach. American Journal of Archaeology, 116, 253-276.

Putkonen, T. (1963). Does early treatment prevent dental changes in congenital syphilis? Acta Dermato-Venereologica, 43, 240.

Radu, C., \& Soficaru, A. D. (2016). Dental developmental defects in a subadult from 16th-19th centuries Bucharest, Romania. International Journal of Paleopathology, 15, 33-38.

Redfern, R. C., DeWitte, S. N., Pearce, J., Hamlin, C., \& Dinwiddy, K. E. (2015). Urban-rural differences in Roman Dorset, England: A bioarchaeological perspective on Roman settlements. American Journal of Physical Anthropolo- $g y, 157,107-120$.

Reid, D., \& Dean, M. (2000). Brief communication: The timing of linear hypoplasias on human anterior teeth. American Journal of Physical Anthropology, 113, 135-139.

Reid, D. J., \& Dean, M. C. (2006). Variation in modern human enamel formation times. Journal of Human Evolution, 50, 329-346.

Roberts, C. A., \& Cox, M. (2003). Health and disease in Britain: from prehistory to the present day. Gloucestershire: Sutton publishing.

Rohnbogner, A., \& Lewis, M. (2016). Dental caries as a measure of diet, health, and difference in non-adults from urban and rural Roman Britain. Dental Anthropology, 29, 16-31.

Sawada, J., Suzuki, T., Yoneda, M., Sato, M., Hirata, K., \& Dodo, Y. (2008). Severe developmental defects of enamel in a human skeleton of the Final Jomon age from the Nakazawahama shell-mound, Iwate, Japan. Anthropological Science, 116, 115-121.

Schuurs, A. (2012). Pathology of the hard dental tissues. Hoboken: John Wiley \& Sons.

Simmonds, A., Márquez-Grant, \& N., Loe, L. (2008). Life and death in a Roman city: Excavation of a Roman cemetery with a mass grave at 120-122 London road, Gloucester. Oxford: Oxford Archaeological Unit Ltd.

Skinner, M. F., Skinner, M. M., Pilbrow, V. C., \& Hannibal, D. L. (2016). An enigmatic hypoplastic defect of the maxillary lateral incisor in recent and fossil orangutans from Sumatra (Pongo abelii) and Borneo (Pongo pygmaeus). International Journal of Primatology, 37, 548-567.

Sundell, S., \& Koch, G. (1984). Hereditary amelogenesis imperfecta. I. Epidemiology and clinical classification in a Swedish child population. Swedish Dental Journal, 9, 157-169.

Van der Veen, M. (2008). Food as embodied material culture: diversity and change in plant food consumption in Roman Britain. Journal of Roman Archaeology, 21, 83-109.

Walker, P. L. (2008). Sexing skulls using discriminant function analysis of visually assessed traits. American Journal of Physical Anthropolo$g y, 136,39-50$.

Weerheijm, K. (2003). Molar incisor hypomineralisation (MIH). European Journal of Paediatric Dentistry, 4, 115-120.

Witzel, C., Kierdorf, U., Schultz, M., \& Kierdorf, H. (2008). Insights from the inside: Histological analysis of abnormal enamel microstruc- 
ture associated with hypoplastic enamel defects in human teeth. American Journal of Physical Anthropology, 136, 400-414.

Wong, H. (2014). Aetiological factors for developmental defects of enamel. Austin Journal of Anatomy, 1.

Wright, J. T. (1985). Analysis of a kindred with amelogenesis imperfecta. Journal of Oral $\mathrm{Pa}$ thology \& Medicine, 14, 366-374.

Xing, S., Guatelli-Steinberg, D., O'Hara, M., Li, J., Wei, P., Liu, W., \& Wu, X. (2016). Micro-CT Imaging and Analysis of Enamel Defects on the Early Late Pleistocene Xujiayao Juvenile. International Journal of Osteoarchaeology, 26, 935-946. 